Brazilian Journal

of Chemical

Engineering

\title{
SYNTHESIS, CHARACTERIZATION AND EVALUATION OF THE HETEROGENEOUS BASIC CATALYST DAPTS-MCM-41 IN THE INTERESTERIFICATION REACTION OF PALM OIL AND PALM KERNEL OIL BLENDS
}

\author{
Ormindo D. Gamallo ${ }^{1 *}$, Hélio F. Machado Júnior ${ }^{2}$ and Tatiana Saldanha ${ }^{1}$ \\ ${ }^{1}$ Universidade Federal Rural do Rio de Janeiro, Departamento de Engenharia de Alimentos, Seropédica, RJ, Brasil. \\ E-mail: odgamallo@gmail.com - ORCID: 0000-0003-3335-3614; ORCID: 0000-0003-4291-4639 \\ ${ }^{2}$ Universidade Federal Rural do Rio de Janeiro, Departamento de Engenharia Química, Seropédica, RJ, Brasil.
}

(Submitted: November 5, 2018 ; Revised: April 4, 2019 ; Accepted: April 7, 2019)

\begin{abstract}
In recent years, the replacement of homogeneous catalysts by heterogeneous catalysts has been investigated as a sustainable alternative technology to obtain different products. In this context, this study investigated the activity of the heterogeneous catalyst DAPTS-MCM-41, obtained from the reaction between the MCM-41 molecular sieve and an organic base 3-ethylenediamine (trimethoxy) propyl silane (DAPTS) in the interesterification reaction of palm oil and palm kernel oil blends. The catalyst was characterized by infrared spectroscopy (FTIR), X-ray diffraction (XRD) and textural analysis (ASAP). The interesterified blends were evaluated by fatty acid profiles (FAME) and solid fat content (SFC). The significant changes observed in the solid fat contents of the blends before and after interesterification led to changes in physical properties due the random distribution of acyl groups on glycerol positions. No undesirable reactions such as degradation and trans isomer formation occurred since the fatty acid composition of the blends remained constant.

Keywords: Vegetable oils; Heterogeneous catalysis; Interesterification; Clean technology.
\end{abstract}

\section{INTRODUCTION:}

Technologies to modify oils and fats have been intensively used in the food industry. These technologies aim to change the physical properties of vegetable oils to make them more suitable for various applications, such as the production of margarine, chocolate toppings, cookies, bakery, and ice cream, pasta and potato chips (Gunstone, 2011; Ribeiro et al., 2007).

Palm oil and palm kernel oil are vegetable oils obtained from the same oleaginous plant: Elaeis guineensis. In a global scenario, palm oil is the most consumed in the world, with a production above 56 million tons in 2012. (USDA, 2015; Monteiro, 2014). The use of palm oil as food corresponds to $80 \%$ of its world production and its consumption has grown significantly, due to its nutritional properties, as well as its other applications (MPOC, 2012).

Currently, the processes commonly used to produce modified fats are chemical and enzymatic interesterification replacing, partial hydrogenation, which generates trans isomers. The chemical interesterification process has low operating costs and large scale application, but as the chemical catalyst used industrially has no specificity, there is a random distribution of acyl groups in the glycerol positions during the reaction. On the other hand, enzymatic interesterification has the advantage of increasing the positional distribution control of acyl groups in the final product as a consequence of the specificity shown by enzymatic catalysts, besides the need for milder

\footnotetext{
* Corresponding author: Ormindo D. Gamallo - E-mail: odgamallo@gmail.com
} 
reactions conditions. But its use is more intended for the manufacture of special fats, when a high selectivity of the biocatalyst is required (Bajaj et al., 2010; Farfan et al., 2015).

In chemical interesterification, moisture-free oils and fats are mixed and heated in the presence of a basic catalyst at a given temperature and for a given time. This process promotes a change in the triglyceride composition depending on the random rearrangement of acyl groups in the glycerol positions, but the fatty acid profile is preserved. At the end of reaction, the catalyst is inactivated by the addition of water to the reaction medium. Two mechanisms are involved in the initiation of the chemical interesterification reaction (Figure 1): the nucleophilic attack on the carbonyl group of the acyl chains and the Claisen condensation, when the base attack occurs on the $\alpha$-hydrogens. Although they are distinct, both mechanisms generate the glyceroxide carbanion, responsible for the propagation step (random rearrangement) (Gamallo et al., 2015).

\section{CHEMICAL INTERESTERIFICATION - INITIATION}

Carbonyl attack mechanism:

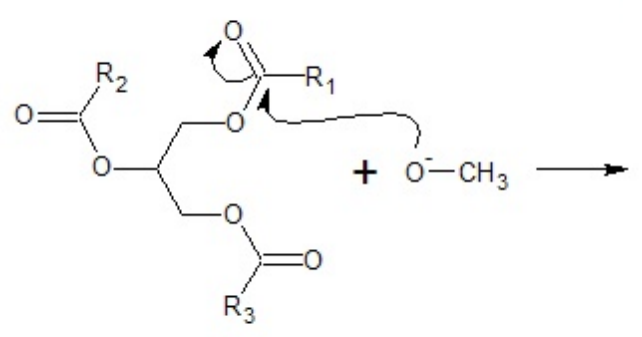<smiles>[R]C(=O)OCC(COC([R])=O)OC1CCC12OCC2[R1]</smiles>

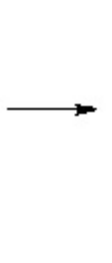<smiles>[R]C(=O)OCC(C[O-])OC([R])=O</smiles><smiles>[R]C(=O)OC</smiles>

Glyderoxide Anion

\section{Claisen mechanism}<smiles>[R]CC(=O)OCC(COC([R3])=O)OC([R2])=O</smiles><smiles>[R]C(=O)OCC(COC([R])=O)OC([R])=O</smiles><smiles>[CH2+]OC</smiles>

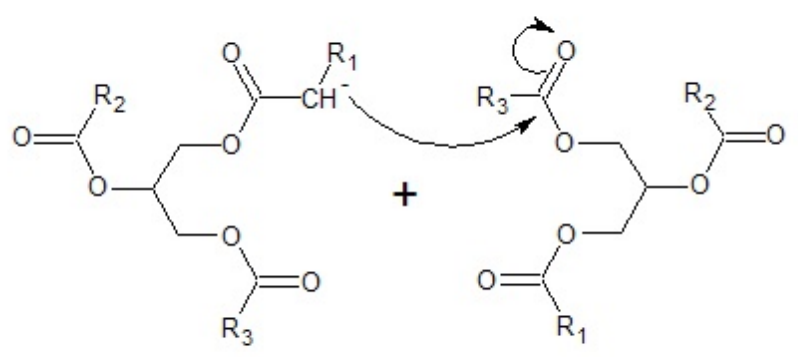

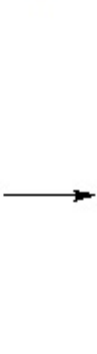

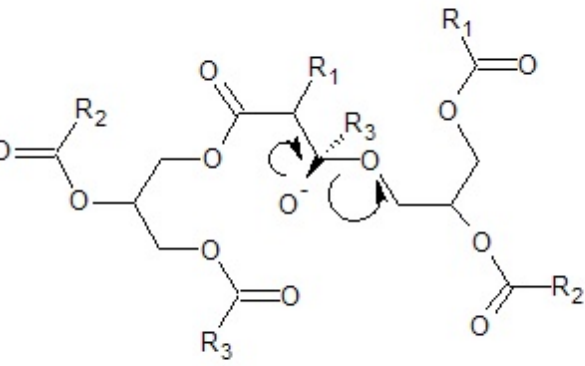<smiles>[R]C(=O)OCC(COC(=O)C([R1])C([R])=O)OC([R])=O</smiles><smiles>[R]C(=O)OCC(C[O-])OC([R2])=O</smiles>

Glyderoxide Anion

Figure 1. Mechanisms for chemical interesterification: Initiation A) Carbonyl addition and B) Claisen mechanism. Adapted from Gamallo et al. (2015). 
In the propagation step (Figure 2), the glyceroxide anion forms a complex with a triglyceride (nucleophilic attack) and then the complex dissociates into a novel triglyceride while regenerating

the glyceroxide anion. The nucleophilic attack can also occur in the anion itself, in the neighboring acyl chains, occurring intraesterification.

Then the reaction is terminated by the addition of water which reacts with the glyceroxide anion to yield a partial glyceride.

In most industrial processes involving these reactions, inorganic or organic bases are used as homogeneous catalysts, and the use of base above the stoichiometric amount to maintain basicity is often necessary (Ono, 2003; Hattori, 2001).

There are some critical points in the chemical interesterification process that should be taken into consideration: The basic catalysts are extremely susceptible to inactivation by water and free fatty acids, and are affected by peroxides, carbon dioxide, and oxygen. Thus, the oil and fat used in the chemical interesterification must be pretreated to remove moisture and free fatty acids. These catalysts are also highly toxic and reactive, requiring special care in storage and handling (Rozenaal, 1992). The separation of the catalyst from the final product is another disadvantage of this process. The inactivation of the catalyst and its removal require the use of reagents and successive washings in water, thus generating a considerable volume of effluent to be treated.

A cleaner technology for the production of these compounds is the replacement of homogeneous catalysts by basic solids, which act as heterogeneous
CHEMICAL INTERESTERIFICATION - TERMINATION

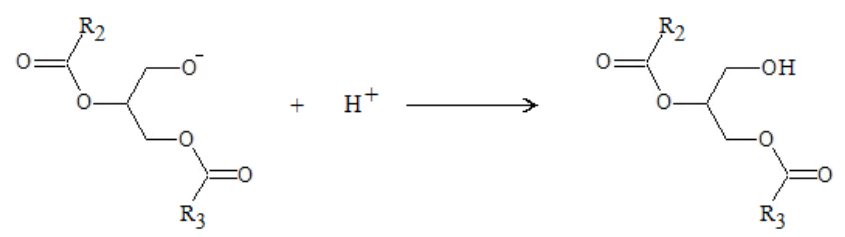

Figure 3. Mechanisms for chemical interesterification: Termination.

catalysts. Currently, studies focused on the development of sustainable chemistry or green chemistry involve primarily the replacement of homogeneous by heterogeneous catalysts. The main advantages of heterogeneous catalysts are their easy removal and the ability to regenerate and reuse them. Furthermore, the fact that these catalysts are not corrosive also represents a great advantage when compared to the homogeneous catalysts. Many studies on the activity of solid compounds with basic properties in chemical reactions have been published since the 1990s, especially focused on biodiesel production (Schuchardt et al. 1998). Among these compounds, potassium fluoride (Corma et al., 1997), alkali metals (Yang and Xie, 2007), zeolites (Luna and Schuchardt, 2001), amino groups stabilized on molecular sieves (such as MCM-41 and SBA-15) (Abdullah et al., 2009), silica gel (Cauvel et al., 1997), clays, alkali metal carbonates, and alkaline earth metals (Corma, 1998) stand out as promising catalysts.

Among the heterogeneous catalysts, mesoporous molecular sieves have emerged as a support for

\section{CHEMICAL INTERESTERIFICATION - PROPAGATION}
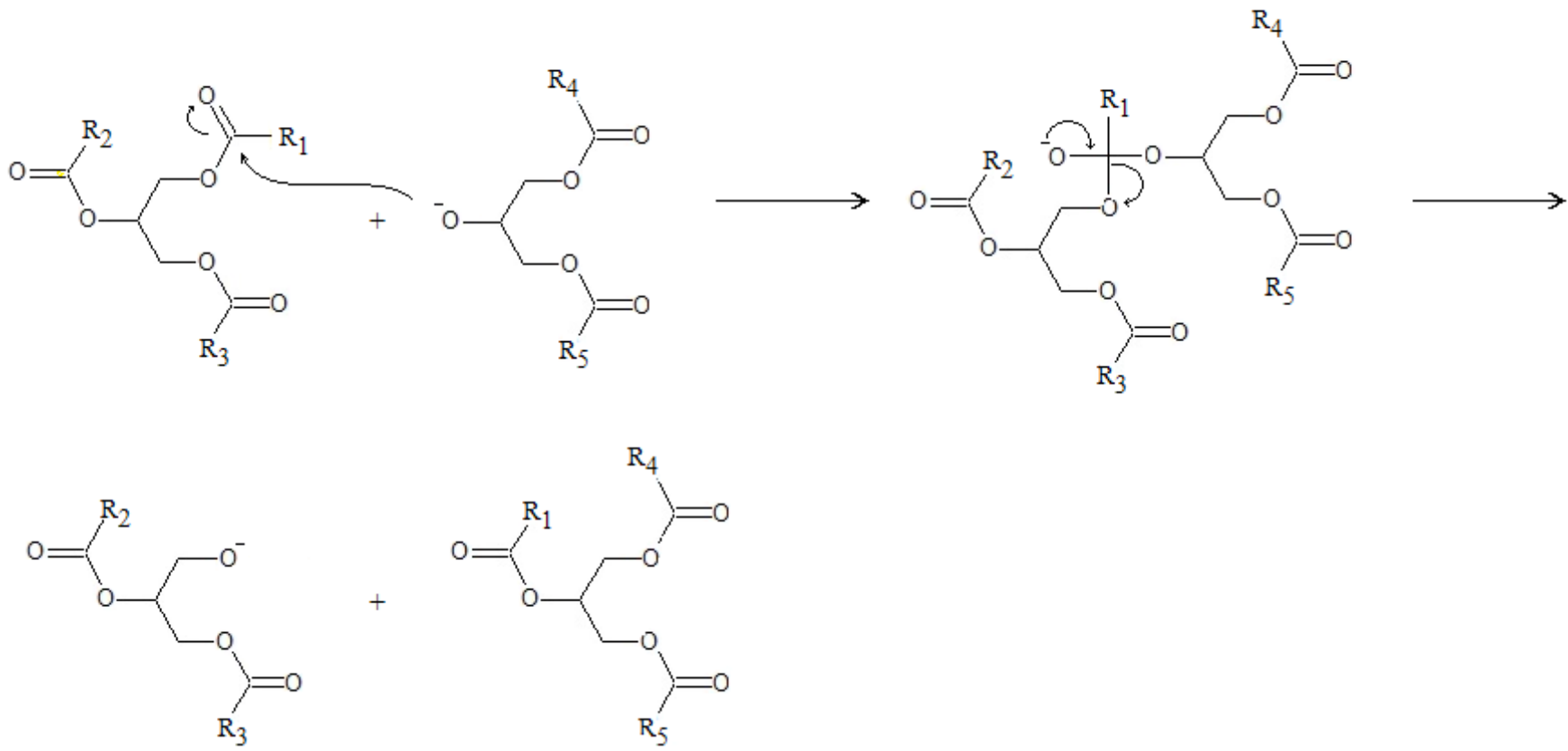

Figure 2. Mechanisms for chemical interesterification: Propagation. 
catalysts due to their high surface area, well-ordered structure, and high pore volume. The MCM-41 mesoporous molecular sieve is characterized by having mesopores (20-40 $\AA$ ) with a very narrow pore diameter distribution. These structures are formed mainly of silica and have a high specific surface area (over 1000 $\mathrm{m}^{2} / \mathrm{g}$ ). Some studies have reported the possibility of producing MCM-41 samples with well-defined and controlled pore diameter in the range of 20-70 $\AA$ only by changing the synthesis conditions (Corma et al., 1997). Due to its high surface area, MCM-41 can be used as a support for basic oxides, and to anchor organic molecules with basic properties, like amines and quaternary ammonium hydroxide salts (Albuquerque et al., 2008; Parida and Rath, 2009). These solids provide basic properties and high surface area, with great potential for use as heterogeneous catalysts. The fact that the pore diameter can be controlled and the possibility of introducing substances with different levels of basicity in the MCM-41 pores may allow adjustments to the properties of these solids and thus be able to catalyze various types of reactions that require distinct levels of basicity, or involve molecules with different sizes, such as in vegetable oils. Furthermore, due to their non-toxic nature (Hudson et al., 2008), molecular sieves have been studied as drug delivery systems. (Vallet-Regi et al., 2001; Piane et al., 2014; Natarajan and Selvaraj, 2014).

Molecular sieves have been also studied as support to circumvent problems associated with the utilization of free lipases in interesterification reactions. Supported lipase can be efficiently removed from reaction products and reused, reducing production costs. In recent studies, lipase immobilized on coreshell structured $\mathrm{Fe}_{3} \mathrm{O}_{4}-\mathrm{MCM}-41$ and on aminopropylfunctionalized hydroxyapatite-encapsulated-y- $\mathrm{Fe}_{2} \mathrm{O}_{3}$ nanoparticles were used as a magnetic biocatalyst for lipid interesterification. In both studies the catalysts showed good activity for the interesterification reaction and easy separation from reaction products by a magnectic field (Xie and Zang, 2016; Xie and Zang, 2017)

In this study, MCM-41 molecular sieve on which the organic base 3-ethylenediamine (trimethoxy) propyl silane (DAPTS) was anchored was synthesized,. Its catalytic activity was evaluated by the interesterification reaction of palm oil and palm kernel oil blends. The catalyst was characterized by infrared spectroscopy (FTIR), X-ray diffraction (XRD), and surface area and porosimetry analysis by gas adsorption measurements (SAP). The interesterification reaction of the blends was carried out in a stainless steel reactor under reduced pressure. The reaction mixtures and the reaction products were characterized by the fatty acid composition (GC-FID) and the solid fat contents (NMR).

\section{MATERIALS AND METHODS:}

\section{Determination of the kinetic diameter of the reactant molecule}

In this study, the kinetic diameter of two triacylglycerols was determined by molecular modeling: 1-palmityl-2 oleyl-3 palmityl glycerol (POP), and 1-palmityl-2 oleyl-3 oleyl glycerol (POO). The geometry of these molecules was optimized through MOPAC 2005 software using the semiempirical methods AM1 and PM3 (Stewart, 1990).

\section{Catalyst preparation}

The synthesis of MCM-41 from a pure silica source was based on the study of Corma et al. (1997), with crystallization temperature and time of $150{ }^{\circ} \mathrm{C}$ for 7 days to yield a solid with large pore size.

In a typical synthesis, an aqueous solution of tetramethyl ammonium silicate from the reaction of $0.59 \%$ amorphous silica (Aerosil 200, Degusa) and $5.29 \% \mathrm{~g}$ of $25 \%$ tetramethyl ammonium hydroxide solution (TMAOH, Sigma-Aldrich) was mixed with a solution containing $2.26 \%$ cetyl trimethyl ammonium bromide (CTABr, Vetec). Then, 2.53\% amorphous silica was added under continuous stirring. The gel formed was placed in a steel Teflon autoclave, and heated at $150^{\circ} \mathrm{C}$ for seven days, under static conditions, at a pressure of $5 \mathrm{~atm}$. The final product was filtered, washed and dried at $80^{\circ} \mathrm{C}$ for 24 hours. The solid was then calcined at $540{ }^{\circ} \mathrm{C} / 6 \mathrm{~h}$.

For synthesis of MCM-41 with basic properties, 3-ethylenediamine (trimethoxy) propyl silane (DAPTS) was used as the precursor. To anchor these substances, $4 \mathrm{~g}$ of previously prepared MCM-41 were suspended in $60 \mathrm{~mL}$ toluene. Then, $4 \mathrm{~g}$ DAPTS was added under stirring and reflux for 2 hours. The methanol formed was distilled off for 30 minutes at $105{ }^{\circ} \mathrm{C}$. After this period, $20 \mathrm{~mL}$ toluene was added, and the system was kept under stirring at $100{ }^{\circ} \mathrm{C}$ for 30 min. The product was recovered by filtration, washed in toluene and hot deionized water, and dried at $60^{\circ} \mathrm{C}$.

\section{Catalyst characterization}

Powder XRD measurements were performed on a Rigaku Miniflex diffractometer, over a $2 \theta$ range with Bragg-Brentano geometry using $\mathrm{Cu} \mathrm{K} \alpha$ radiation. The scanning of the samples was performed from 0 to $10(2 \theta)$ at intervals of $0.020^{\circ}$, and acquisition time of $2 \mathrm{~s}$. $\mathrm{N}_{2}$ adsorption-desorption isotherms at $77 \mathrm{~K}$ were obtained using an ASAP 2020 specific area analyzer (Micromeritics). The isotherms were treated by the BET method for obtaining the surface area and pore diameter, and by the BJH method for obtaining pore volume. The FT-IR spectra of the samples were obtained with a Thermo Nicolet 6700 FT-IR spectrometer, using the $\mathrm{KBr}$ cell technique and 
readings were made in the range of 400 to $4000 \mathrm{~cm}^{-1}$. MCM-41 samples were evaluated before and after their functionalization with DAPTS.

\section{Interesterification reaction}

The refined palm oil and palm kernel oil were supplied by Agropalma SA.

Binary blends of palm oil and palm kernel oil with ratios of 100/0, 80/20,60/40, 50/50, 40/60, 20/80 and $0 / 100(\mathrm{w} / \mathrm{w})$ were used as the starting oil mixture. The blend samples were prepared after complete melting at $70{ }^{\circ} \mathrm{C}$, and again solidified and stored under refrigeration.

Portions of $100 \mathrm{~mL}$ of the blends were dried in a flask under reduced pressure and agitation at $80{ }^{\circ} \mathrm{C}$ for $30 \mathrm{~min}$. The interesterification was carried out by the addition of $1.0 \mathrm{~g}$ of DAPTS-MCM 41 previously activated at $200^{\circ} \mathrm{C} / 2 \mathrm{~h}$ under reduced pressure. The different blends were interesterified at $100{ }^{\circ} \mathrm{C}$ for 30 minutes under reduced pressure and agitation. At the end of reaction, the heating and stirring were stopped, and the reaction product was immediately filtered to remove the catalyst and then stored at $-15{ }^{\circ} \mathrm{C}$ for subsequent analysis.

\section{Product analysis}

The fatty acid compositions of the interesterified products were determined after complete conversion of fat acid residues into their corresponding fatty acid methyl esters (FAME) according to the AOAC 969.33 method (AOAC, 2002). The chromatographic analysis was performed according to the AOAC 985.21 method (AOAC, 2002) on a Shimadzu gas chromatograph GC-2010 Plus equipped with an auto injector, a split injector and a flame ionization detector (FID). $1 \mu \mathrm{L}$ of samples were injected onto a CP SIL-88 column (100\% cyanopropylpolysiloxane, $100 \mathrm{~m}, 0.25 \mathrm{~mm}$ ID and $0.20 \mu \mathrm{m}$ film thickness) using hydrogen as the carrier gas at $70 \mathrm{kPa}$ with a split ratio of 1:50. The injector and detector temperatures were set at 250 and $260^{\circ} \mathrm{C}$, respectively. The oven temperature was initially held at $100{ }^{\circ} \mathrm{C}$ for $5 \mathrm{~min}$, programmed to increase to 230 ${ }^{\circ} \mathrm{C}$ at a rate of $5{ }^{\circ} \mathrm{C} / \mathrm{min}$, and then held isothermally for another $5 \mathrm{~min}$. Again the temperature was raised to $240{ }^{\circ} \mathrm{C}$ at $5{ }^{\circ} \mathrm{C} / \mathrm{min}$ and held for 11 minutes. The FAME composition was identified by comparing the retention time of the peaks with the respective standards of FAME. The relative FAME content was obtained by area normalization and expressed as a mass percentage. All samples were analyzed in triplicate, and the reported values are the average of three determinations.

The solid fat content was determined by nuclear magnetic resonance (NMR) in Bruker Minispec equipment, according to the AOCS CD-16b-93 method (AOCS, 2000), by the direct method for nonstabilizing fats $\left(100{ }^{\circ} \mathrm{C} / 15 \mathrm{~min}, 60{ }^{\circ} \mathrm{C} / 5 \mathrm{~min}, 0{ }^{\circ} \mathrm{C}\right.$
/ $60 \mathrm{~min}$ ), with serial readings, at temperatures of 10 , $20,25,30,35,40$, and $45^{\circ} \mathrm{C}$, staying $30 \mathrm{~min}$ at each temperature.

\section{RESULTS AND DISCUSSION:}

\section{Catalyst characterization}

The kinetic diameters obtained by minimization of the internal energy (IE) of the POP and POO molecules were $38.74 \AA$ and $38.08 \AA$, respectively. The molecular structure of POP and PPO is a relevant factor in choosing the molecular sieve. The MCM41 type sieves have pore diameters ranging between 30 and $75 \AA$, depending on the synthesis conditions. Corma et al. (1997) obtained MCM-41 with a pore diameter of about $66 \AA$ at a crystallization temperature of $150^{\circ} \mathrm{C}$ for 7 days.

$\mathrm{X}$-ray diffraction is the most common technique for investigating the formation of mesoporous materials and other porous materials. The $\mathrm{a}_{0}$ values for the calcined MCM-41 and after DAPTS incorporation were respectively $56.97 \AA$ and $58.34 \AA$. These similar values indicate no changes in the hexagonal structure of MCM-41 after DAPTS incorporation.

Figure 4A shows the XRD patterns of the calcined MCM-41 (MCM-41), and after functionalization (DAPTS-MCM-41), showing a characteristic profile of this molecular sieve (Oliveira et al., 2014). Since it is made up of amorphous silica, no peaks were observed in regions of larger angles.

The peaks at $2.27^{\circ}$ (high intensity with $\mathrm{d}_{100}=49.34$ $\AA$ ) and three peaks of lower intensity between $3^{\circ}$ and $6^{\circ}$ are related to its well-ordered hexagonal lattice, where a pore is surrounded by six others, thus generating its characteristic reflections (Wang et al., 2012). In the diffractogram shown in figure $4 \mathrm{~A}$, the $\mathrm{d}_{100}$ values of the peaks with high intensity were higher when compared with a typical synthesis of this material $\left(150^{\circ} \mathrm{C} / 24 \mathrm{~h}\right)$ (Corma et al., 1997). This variation may be due to the binomial crystallization time / temperature of the catalyst in this study $\left(150^{\circ} \mathrm{C} / 7\right.$ days $)$. According to Corma et al. (1997), long crystallization times at 150 ${ }^{\circ} \mathrm{C}$ can favor the increase of the MCM-41pore size.

The incorporation of DAPTS in MCM-41 did not cause significant changes in the intensity and position of the peaks, indicating no changes in the order of the hexagonal lattice in the molecular sieve. Similar results were obtained by Fasolo et al. (2006) for amine incorporation into MCM-41 molecular sieves for chalcone synthesis.

Anchoring of organic bases such as DAPTS occurs through the reaction of hydroxyls from the silanol groups present on the catalyst surface, with the alkoxy groups of DAPTS. Figure 4B shows the FTIR spectra of the calcined MCM-41 samples and after DAPTS incorporation. With respect to the calcined MCM-41, the broad band at $3456 \mathrm{~cm}^{-1}$ is due to both the axial 


\section{Catalyst Characterization}

A. XRD

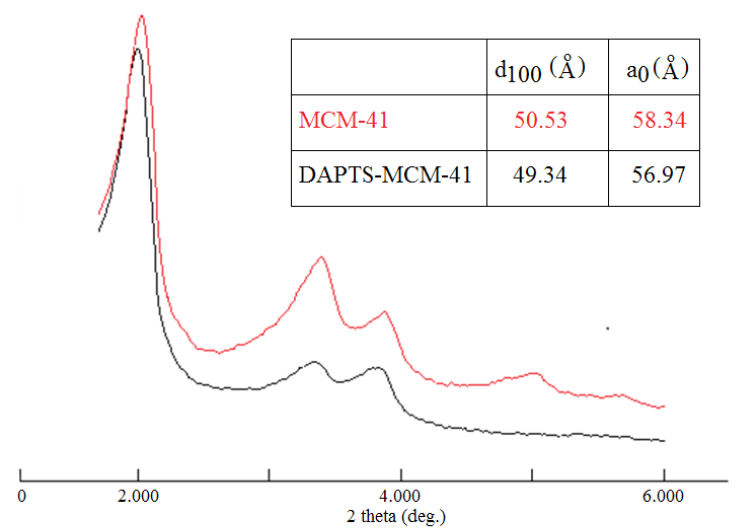

B. FTIR

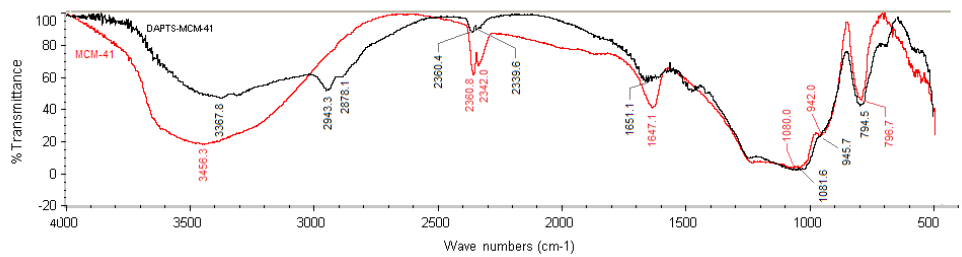

C. Adsorption / Desorption Isotherms
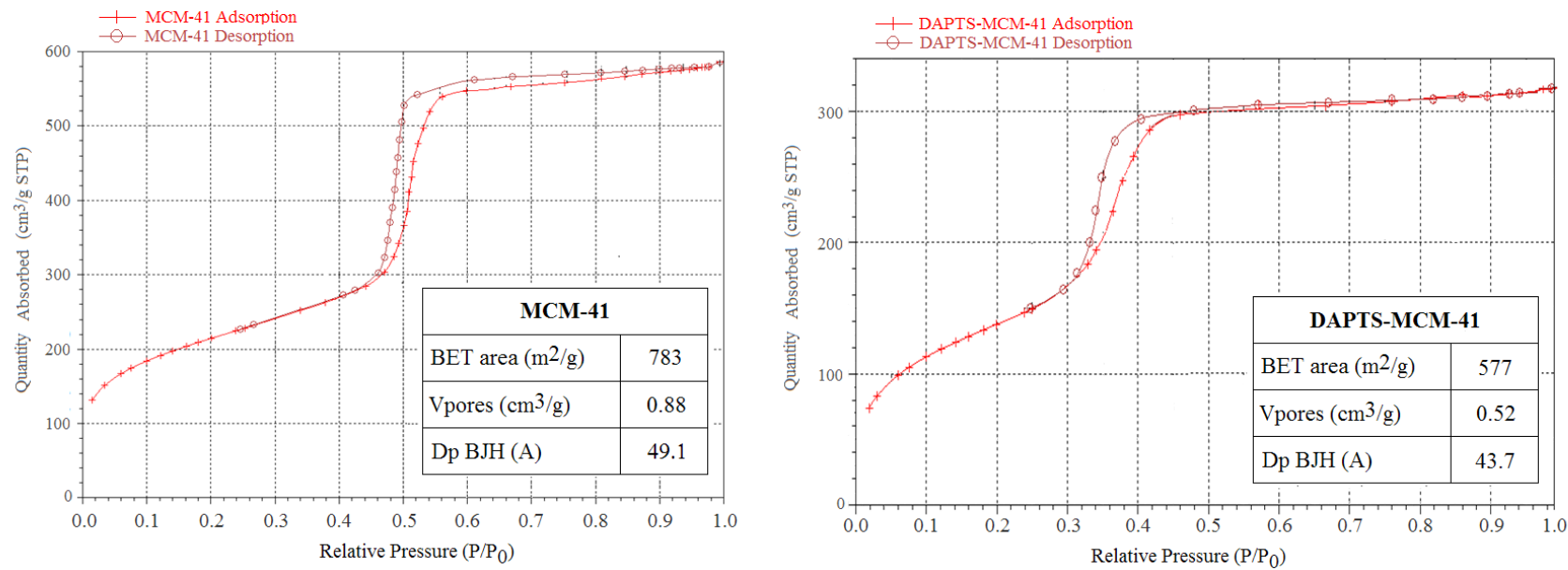

Figure 4. A. XRD patterns of the calcined MCM-41 and MCM-41 functionalized with DAPTS. B. FTIR spectra of calcined MCM-41 samples before and after DAPTS incorporation. C. Adsorption / desorption isotherms of calcined MCM-41 and MCM-41 functionalized with DAPTS.

deformation of the hydroxyls of the silanol group on the catalyst surface, and the hydroxyl groups derived from adsorbed water in the sample, the latter confirmed with the presence of the band at $1647 \mathrm{~cm}^{-1}$, attributed to the angular hydroxyl deformation. The vibration modes related to Si-O-Si in MCM-41 can be observed at $1080 \mathrm{~cm}^{-1}$ (axial deformation) and $790 \mathrm{~cm}^{-1}$ (angular deformation). These signals come from the silica on the catalyst surface. The band at $942 \mathrm{~cm}^{-1}$ can be assigned to angular deformation of defective $\mathrm{Si}-\mathrm{OH}$ groups, i.e., Si-OH groups from non-condensed silica in the catalyst wall (material dispersed).

The FTIR spectrum for MCM-41 after DAPTS anchoring (DAPTS-MCM-41) showed a decreased intensity of the axial deformation band of the hydroxyl groups due to the disappearance of the silanol groups that reacted with DAPTS. Also two bands at $2943 \mathrm{~cm}^{-1}$ and $2878 \mathrm{~cm}^{-1}$ can be seen, assigned respectively to the axial and angular deformations of the $\mathrm{CH}_{2}$ groups from the anchored DAPTS.

The MCM-41exhibited characteristics of a type IV isotherm (Figure 4C), according to the IUPAC classification, which is characteristic of mesoporous materials with a multilayer adsorption cycle, with appearance of an inflection point from the relative pressures $\left(\mathrm{P} / \mathrm{P}_{0}\right)$ in the range from 0.30 to 0.50 , associated with capillary condensation in the mesopores (IUPAC, 1985). Another important characteristic of MCM-41 is the presence of hysteresis, which is the phenomenon of the difference between adsorption and desorption mechanisms, that is typical of porous materials with a narrow size distribution of cylindrical pores and spherical particles (Schwanke and Pergher 2012). 
Figure 4C show the nitrogen adsorption / desorption isotherms of MCM-41 and DAPTS-MCM-41. The isotherms have the same profile as a type IV isotherm, characteristic of mesoporous materials. However, its textural properties showed slightly higher values when compared to the values found in the literature, which again may be due to the crystallization conditions of the catalyst used in this study, which favor the formation of MCM-41 with larger diameter pores (Corma et al., 1997; Oliveira et al., 2014).

A significant reduction in MCM-41 textural properties after functionalization with DAPTS was observed. This type of variation may be due to the anchoring on the MCM-41 surface, increasing the wall thickness and even blocking pore access. The loss of crystallinity or the change in molecular sieve structure as a function of the base incorporation may also be associated with this type of observation, but no change was observed in the type of isotherm after functionalization, indicating no change in MCM- 41 structure, and confirming the results obtained by X-ray diffraction.

\section{Product analysis}

The application of heterogeneous catalysts has many advantages in comparison to homogeneous catalysts. DAPTS-MCM-41 could be easily recovered from the reaction mixture, which is of interest for the separation process. Besides, no variation was observed in the color of the reaction mixture, as occurs in interesterification with the conventional catalyst (Liu and Lampert, 1999).

Table 1 shows the fatty acid composition of palm oil and palm kernel oil blends, before and after interesterification. The compositions of palm oil and palm kernel oil are consistent with the literature (Gunstone, 2011), and within commercial specifications of the manufacturers.
The results show that the fatty acid composition of the reaction products is very similar to that found for the original respective blends, since no significant changes were observed in fatty acid composition of the samples. The same behavior was observed in other studies of the interesterification of vegetable oils with heterogeneous catalysts. In the study of interesterification of soybean oil and lard blends catalyzed by SBA-15-pr-NR $\mathrm{OH}$, Xie and Qi (2013) obtained the same fatty acid profile of the starting material in the final product. This result demonstrates that no undesirable reactions such as decomposition or isomerization of fatty acids had occurred.

The solid fat content accounts for many of the characteristics of fat and is one of the determining factors in the plasticity of fats. According to Lida and Ali (1998), the fat behavior can be predicted by assessing the solid fat content at different temperatures. For example, a fat with satisfactory spreadability at refrigeration temperature (characteristic for margarine manufacturing) should contain a maximum of $32 \%$ solids in the temperature range from 4 to $10{ }^{\circ} \mathrm{C}$. To be resistant to oil exudation, fat should have solid contents less than $10 \%$ at $20-22{ }^{\circ} \mathrm{C}$. According to the authors, solid fat in the range $35-37^{\circ} \mathrm{C}$ confers positive sensory properties to the product.

Table 2 shows the solid fat content of the blends, both before and after interesterification. After interesterification, an increase in the solid fat content of the blends containing higher palm oil ratio (palm oil, 80/20 and 60/40) and a decrease in the blends with higher oil palm kernel ratio (40/60, 20/80 and palm kernel oil) were observed. Similar results have been reported in the literature for chemical interesterification via homogeneous catalysis. Laning (1985) reported an increase in the solid fat content of interesterified palm oil due to the higher levels of trisaturated triglycerides.

Table 1. Fatty acids (FA) composition of palm oil and palm kernel oil blends before and after interesterification.

\begin{tabular}{|c|c|c|c|c|c|c|c|c|}
\hline FA (\%) & & Palm & $80 / 20$ & $60 / 40$ & $50 / 50$ & $40 / 60$ & $20 / 80$ & Palm Kernel \\
\hline \multirow{2}{*}{$\mathrm{C}_{8}$} & Before & - & $0.8 \pm 0.0$ & $1.2 \pm 0.0$ & $1.7 \pm 0.1$ & $2.0 \pm 0.1$ & $2.6 \pm 0.0$ & $3.3 \pm 0.0$ \\
\hline & After & - & $0.7 \pm 0.0$ & $1.1 \pm 0.0$ & $1.5 \pm 0.1$ & $1.9 \pm 0.0$ & $2.4 \pm 0.1$ & $3.3 \pm 0.2$ \\
\hline \multirow{2}{*}{$\mathrm{C}_{10}$} & Before & - & $0.7 \pm 0.0$ & $1.3 \pm 0.0$ & $1.8 \pm 0.1$ & $2.1 \pm 0.1$ & $2.7 \pm 0.0$ & $3.4 \pm 0.0$ \\
\hline & After & - & $0.6 \pm 0.0$ & $1.2 \pm 0.0$ & $1.7 \pm 0.0$ & $2.0 \pm 0.0$ & $2.9 \pm 0.1$ & $3.3 \pm 0.1$ \\
\hline \multirow{2}{*}{$\mathrm{C}_{12}$} & Before & $0.3 \pm 0.0$ & $10.0 \pm 0.0$ & $19.3 \pm 0.6$ & $24.6 \pm 1.0$ & $28.9 \pm 0.4$ & $38.6 \pm 0.8$ & $48.2 \pm 1.4$ \\
\hline & After & $0.4 \pm 0.0$ & $9.7 \pm 0.5$ & $19.5 \pm 0.7$ & $24.4 \pm 0.7$ & $28.6 \pm 1.1$ & $38.2 \pm 1.3$ & $48.7 \pm 1.1$ \\
\hline \multirow{2}{*}{$\mathrm{C}_{14}$} & Before & $1.4 \pm 0.0$ & $4.4 \pm 0.0$ & $7.1 \pm 0.2$ & $9.0 \pm 0.3$ & $10.3 \pm 0.4$ & $13.2 \pm 0.3$ & $16.2 \pm 0,7$ \\
\hline & After & $1.4 \pm 0.0$ & $4.5 \pm 0.1$ & $7.2 \pm 0.1$ & $9.2 \pm 0.1$ & $10.1 \pm 0.5$ & $13.0 \pm 0.6$ & $16.4 \pm 0.4$ \\
\hline \multirow{2}{*}{$\mathrm{C}_{16}$} & Before & $43.1 \pm 0.7$ & $36.0 \pm 0.9$ & $29.7 \pm 0.9$ & $25.4 \pm 0.4$ & $22.2 \pm 0.9$ & $15.3 \pm 0.4$ & $8.4 \pm 0.3$ \\
\hline & After & $43.6 \pm 0.2$ & $36.3 \pm 1.0$ & $30.0 \pm 1.2$ & $25.2 \pm 0.6$ & $22.5 \pm 0.7$ & $15.2 \pm 0.7$ & $8.6 \pm 0.3$ \\
\hline \multirow{2}{*}{$\mathrm{C}_{18}$} & Before & $4.7 \pm 0.2$ & $4.2 \pm 0.1$ & $3.8 \pm 0.0$ & $3.5 \pm 0.1$ & $3.5 \pm 0.1$ & $2.9 \pm 0.0$ & $2.5 \pm 0.1$ \\
\hline & After & $4.8 \pm 0.0$ & $4.4 \pm 0.1$ & $3.9 \pm 0.1$ & $3.5 \pm 0.2$ & $3.6 \pm 0.1$ & $3.1 \pm 0.1$ & $2.5 \pm 0.1$ \\
\hline \multirow{2}{*}{$\mathrm{C}_{18: 1}$} & Before & $40.3 \pm 0.4$ & $35.2 \pm 1.2$ & $30.6 \pm 0.7$ & $27.7 \pm 0.3$ & $25.3 \pm 0.9$ & $20.4 \pm 0.2$ & $15.3 \pm 0.5$ \\
\hline & After & $40.5 \pm 0.8$ & $35.9 \pm 1.2$ & $30.7 \pm 0.5$ & $27.9 \pm 0.7$ & $25.5 \pm 1.1$ & $20.4 \pm 0.8$ & $15.0 \pm 0.4$ \\
\hline \multirow{2}{*}{$\mathrm{C}_{18: 2}$} & Before & $9.8 \pm 0.4$ & $8.2 \pm 0.3$ & $6.6 \pm 0.2$ & $5.9 \pm 0.1$ & $5.4 \pm 0.1$ & $3.9 \pm 0.2$ & $2.3 \pm 0.0$ \\
\hline & After & $10.1 \pm 0.5$ & $8.4 \pm 0.2$ & $6.7 \pm 0.1$ & $6.2 \pm 0.3$ & $5.5 \pm 0.0$ & $4.1 \pm 0.1$ & $2.3 \pm 0.1$ \\
\hline
\end{tabular}

$\mathrm{C}_{8}$ Caprilic acid; $\mathrm{C}_{10}$ Capric acid; $\mathrm{C}_{12}$ Lauric acid; $\mathrm{C}_{14}$ Mirystic acid; $\mathrm{C}_{16}$ Palmitic acid; $\mathrm{C}_{18}$ stearic acid; $\mathrm{C}_{18: 1}$ Oleic acid; $\mathrm{C}_{18: 2}$ Linoleic acid. 
Table 2. Solid fat content of palm oil and palm kernel oil blends before and after interesterification.

\begin{tabular}{|c|c|c|c|c|c|c|c|c|c|c|c|c|c|c|}
\hline \multirow{2}{*}{$\begin{array}{c}\mathrm{T} \\
\left({ }^{\circ} \mathrm{C}\right)\end{array}$} & \multicolumn{2}{|c|}{ Palm oil } & \multicolumn{2}{|c|}{$80 / 20$} & \multicolumn{2}{|c|}{$60 / 40$} & \multicolumn{2}{|c|}{$50 / 50$} & \multicolumn{2}{|c|}{$40 / 60$} & \multicolumn{2}{|c|}{$20 / 80$} & \multicolumn{2}{|c|}{ Palm kernel oil } \\
\hline & Before & After & Before & After & Before & After & Before & After & Before & After & Before & After & Before & After \\
\hline 10 & 47.5 & 52.3 & 51.7 & 56.9 & 55.7 & 56.8 & 58.0 & 57.7 & 60.0 & 58.3 & 64.2 & 60.7 & 68.4 & 66.3 \\
\hline 20 & 19.8 & 33.8 & 23.5 & 38 & 27.2 & 41.2 & 29.1 & 35.6 & 30.9 & 33.9 & 34.6 & 31.7 & 38.3 & 31.4 \\
\hline 25 & 10.6 & 20.5 & 11.5 & 18.6 & 12.4 & 21.2 & 12.9 & 22.3 & 13.3 & 17.6 & 14.2 & 12.8 & 15.1 & 9.5 \\
\hline 30 & 6.5 & 12.8 & 5.2 & 7.9 & 3.9 & 6.7 & 3.3 & 4.3 & 2.6 & 3.8 & 1.3 & 1.1 & 0.0 & 0.0 \\
\hline 35 & 3.1 & 5.6 & 2.5 & 4.0 & 1.9 & 2.5 & 1.6 & 1.5 & 1.2 & 1.1 & 0.6 & 0.2 & 0.0 & 0.0 \\
\hline 40 & 1.7 & 3.7 & 1.4 & 2.3 & 1.0 & 1.5 & 0.5 & 1.0 & 0.0 & 0.0 & 0.0 & 0.0 & 0.0 & 0.0 \\
\hline 45 & 0.1 & 0.2 & 0.1 & 0.1 & 0.0 & 0.0 & 0.0 & 0.0 & 0.0 & 0.0 & 0.0 & 0.0 & 0.0 & 0.0 \\
\hline
\end{tabular}

For the interesterified palm kernel oil, this behavior is reversed since the reaction promotes the formation of triglycerides with intermediate degrees of unsaturation. Grimaldi et al. (2001) studied the physical properties of interesterified palm oil and palm kernel oil blends in the presence of sodium methoxide, and observed an increase in the solid fat content of the blends containing at least 40\% palm oil. D'Agostini and Gioielli (2002) studied the chemical interesterification of binary and ternary blends of palm fat, palm oil, and medium chain triglycerides, and found that the solid fat content depends on the levels of palm oil, with an increase in solid fat content with higher levels of palm oil.

The melting and crystallization behavior of the fat blends is directly affected by the type of interactions between the triglyceride molecules, leading to the formation of a solid solution when there is compatibility between the components, or formation of a eutectic system in the case of incompatibility of the components. In this case, the solubility in the solid state is not complete (Soares et al., 2009). The iso solid curves, which present a depression, are a useful tool to verify the eutectic system in fat blends. The iso solid curves are obtained from the solid fat content of the blends at a constant temperature (Lefebvre, 1983). Figure 5 shows the iso-solid curves of palm oil and palm kernel oil blends, before (A) and after (B) interesterification.

Palm oil and palm kernel oil have significant differences in the length of the carbon chains of the fatty acids and, therefore, different molecular weights of the prevalent fatty acids, in addition to having different polymorphic forms. Given these differences, the compatibility of the crystalline lattice of palm oil and palm kernel oil blends is difficult, causing a softening characteristic of the eutectic effect (D'Agostini and Gioielli, 2002). This effect can be seen in the results in Figure 5A in which all blends exhibited an eutectic effect, which was almost eliminated after the interesterification (Figure 5B), except for the 5\% iso-solid curve, evidencing the rearrangement of fatty acids during interesterification.

The rearrangement of fatty acids in the glycerol molecules may change the physical properties of the interesterified product. When interesterification leads to an increase in melting point, a significant increase

\section{Iso Solids Curves}

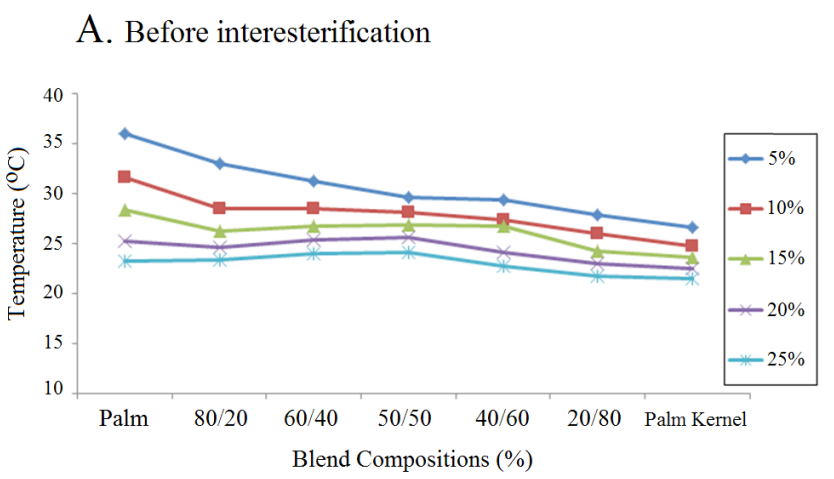

B. After interesterification

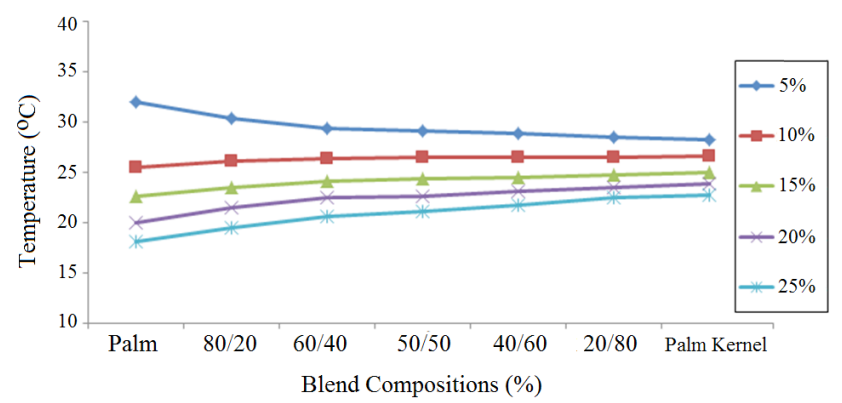

Figure 5. Iso-solids curves of the blends before (A) and after $(\mathrm{B})$ interesterification.

in disaturated and trisaturated triglyceride levels is observed due to the insertion of saturated fatty acids in the sn-2 position of glycerol. When a lower melting point is found after interesterification, the insertion of unsaturated fatty acids in the sn-2 position of glycerol is most pronounced (Silva and Gioielli, 2006). There was a decrease in the melting point of the blends with the increase in kernel oil levels before and after interesterification. However, when the blends with similar composition were evaluated before and after interesterification, there was an increase in melting point of the blends with higher palm oil content, and a decrease in the blends with higher kernel oil levels. The fatty acid composition of the blends (Table 1) shows that, although palm kernel oil has a higher saturated fatty acid level (about $82 \%$ ), the long chain saturated fatty acids (C16 and $\mathrm{C} 18)$ are only $11 \%$ of the total 
fatty acids, whereas in palm oil these percentages exceed $47 \%$.

\section{CONCLUSIONS}

The results obtained in the characterization of mesoporous molecular sieve MCM-41 revealed a successful anchoring of 3-propyl ethylenediamine groups on its surface. The fatty acid profile revealed the maintenance of the fatty acid compositions of palm oil and palm kernel oil, since no significant differences were observed in the blends before and after interesterification. This analysis also revealed no formation of trans isomers after the reaction. The interesterification of palm oil and kernel palm oil blends in the presence of the catalyst DAPTSMCM41 provided changes in their physical properties, minimizing the incompatibility between them, probably due to the rearrangement of fatty acids on the glycerol molecule. Thus, it can be concluded that the mesoporous molecular sieve MCM-41 modified with DAPTS has proven to be a promising substitute for the sodium methoxide catalyst used industrially. In this way, a cleaner technology can be employed, reducing costs with the steps of neutralization and removal of the conventional catalyst, as well as the costs of wastewater treatments generated in these steps.

\section{REFERENCES}

Abdullah, A.Z., Razali, N., Lee, K.T. Optimization of Mesoporous K/SBA-15 Catalyzed Transesterification of Palm Oil Using Response Surface Methodology. Fuel Processing Technology, 90, 958-964 (2009). https://doi.org/10.1016/j. fuproc.2009.03.023

Albuquerque, M.C.G., Urbistondob, I.J., González, J.S., Roblesb, J.M.M., Tostb, M., Castellón, E.R., López, A.J., Azevedo, D.C.S., Cavalcante Jr, C.L., Torres, P.M. CaO Supported on Mesoporous Silicas as Basic Catalysts for Transesterification Reactions. Applied Catalysis A: General, 334, 35-43 (2008). https://doi.org/10.1016/j.apcata.2007.09.028

AOAC, Association of Official Analytical Chemists, Official Methods of Analysis, AOAC International, $18^{\text {th }}$ ed, Washington, (2002).

AOCS, Official Methods and Recommended Pratices of the American Oil Chemists' Society, $5^{\text {th }}$ ed, Champaign (2003).

Bajaj, A., Johan, P., Jha, P.N., Mehrotra, R. Biodiesel Production Through Lipase Catalyzed Transesterification: An Overview. Journal of Molecular Catalysis B: Enzymatic, 62, 9-14 (2010). https://doi.org/10.1016/j.molcatb.2009.09.018

Cauvel, A., Renar, G., Brunel, D. Monogliyceride Sinthesys by Heterogeneous Catalysis Using MCM-41 Type Sílicas Functionalized with Amino
Groups. The Journal of Organic Chemistry, 62, 749-751 (1997). https://doi.org/10.1021/jo9614001

Corma, A., Kan, Q., Navarro, M.T., Pariente, J.P., Rey, F. Synthesis of MCM-41 with Different Pore Diameters without Addition of Auxiliary Organics. Chemistry of Materials, 9, 2123-2126 (1997). https://doi.org/10.1021/cm970203v

Corma, A. A Preparation and Catalytic Properties of New Mesoporous Materials. Topics in Catalysis, 4, 249-260 (1998). https://doi. org/10.1023/A:1019108810337

D’Agostini, D., Gioielli, L.A. Distribuição Estereoespecífica de Lipídios Estruturados a Partir de Gorduras de Palma, Palmiste e Triacilgliceróis de Cadeia Média. Revista Brasileira de Ciências Farmacêuticas, 38, 345-354 (2002). https://doi. org/10.1590/S1516-93322002000300010

Fasolo, W.V., Bastos, F.S., Fernandes, L.D. Síntese de MCM-41 Apresentando Diferentes Tamanhos de Poros e Propriedades. Revista Universidade Rural, Série Ciências Exatas e da Terra, 25, 01-08 (2006).

Farfan, M., Álvarez, A., Gárate, A., Bouchon, P. Comparison of Chemical and Enzymatic Interesterification of Fully Hydrogenated Soybean Oil and Walnut Oil to Produce a Fat Base with Adequate Nutritional and Physical Characteristics. Food Technology and Biotechnology, 53, 361-366 (2015). https://doi.org/10.17113/ftb.53.03.15.3854

Gamallo, O.D., Machado Jr, H.F.M., Saldanha, T. Modified Fats by Heterogeneous Catalysis: Changes on the Way to Green Chemistry. Advance Journal of Food Science and Technology, 9, 584591 (2015). https://doi.org/10.19026/ajfst.9.1970

Grimaldi, R., Gonçalves, L.A.G., Gioielli, L.A., Simões, I.S. Interactions in Interesterified Palm and Palm Kernel Oils Mixtures, I-Solid Fat Content and Consistency. Grasas y Aceites, 52, 349-354 (2001). https://doi.org/10.3989/gya.2001.v52.i6.341

Gunstone, F.D. Vegetable Oils in Food Technology. Composition, Properties and Uses, Wiley-Blackwell, USA (2011). https://doi. org/10.1002/9781444339925

Hattori, H. Solid Base Catalysts: Generation of Basic Sites and Application to Organic Synthesis. Applied Catalysis, 222, 247-259 (2001). https:// doi.org/10.1016/S0926-860X(01)00839-0

Hudson, S.P., Padera, R.F., Langer, R., Kohane, D.S. The Biocompatibility of Mesoporous Silicates. Biomaterials, 29, 4045-4055 (2008). https://doi. org/10.1016/j.biomaterials.2008.07.007

IUPAC, Recommendations, Pure and Applied Chemistry, 57, 603-619 (1985). https://doi. org/10.1351/pac198557040603

Laning, S.J. Chemical Interesterification of Palm, Palm Kernel and Coconut Oils. Journal of the American Oil Chemists' Society, 62, 400-407 (1985). https:// doi.org/10.1007/BF02541411 
Lefebvre, J. Finished Product Formulation. Journal of the American Oil Chemists' Society, 60, 295-300 (1983). https://doi.org/10.1007/BF02543503

Lida, H.M.D., Ali, A.R. Physical-Chemical Characteristics of Palm-Based Oil Blends for the Production of Reduced Fat Spreads. Journal of the American Oil Chemists' Society, 75, 16251631 (1998). https://doi.org/10.1007/s11746-9980103-y

Liu, L., Lampert, D. Monitoring Chemical Interesterification. Journal of the American Oil Chemists' Society, 76, $783-787$ (1999). https://doi. org/10.1007/s11746-999-0066-7

Luna, F.J., Schuchardt, U. Modificações em Zeólitas para Uso em Catálise. Química Nova, 6, 885892 (2001). https://doi.org/10.1590/S010040422001000600027

MPOC (Malasian Palm Oil Council). Palm Oil: A versatile ingredient for food and non-food applications. 2012. <http://www.mpoc.org.my/ upload/POTS_INDIA2012_DatukDrChoo.pdf $>$ (Acess: 02/12/2013).

Monteiro, K.F.G., Homma, A.K.O. Diferentes sistemas de produção com palma de óleo (Elaeis guineensis Jaq.) e a participação do Brasil no cenário internacional, Observatótio de la Economia Latino-Americana, 200 (2014).

Natarajan, S.K., Selvaraj, S. Mesoporous Silica Nanoparticles: Importance of Surface Modifications and its Role in Drug Delivery. RSC Advances, 4, 14328-14334 (2014). https://doi.org/10.1039/ c4ra00781f

Ono, Y. Solid Base Catalysts for the Synthesis of Fine Chemicals. Journal of Catalysis, 216, 406415 (2003). https://doi.org/10.1016/S00219517(02)00120-3

Oliveira, T.G., Machado, S.W.M., Santos, S.C.G., Souza, M.J.B., Pedrosa, A.M.G. Adsorção de $\mathrm{CO}_{2}$ em Peneiras Moleculares Micro e Mesoporosas. Química Nova, 37, 610-617 (2014).

Parida, K.M., Rath, D. Amine Functionalized MCM-41: An Active and Reusable Catalyst for Knoevenagel Condensation Reaction. Journal of Molecular Catalysis A: Chemical, 310, 93-100 (2009). https:// doi.org/10.1016/j.molcata.2009.06.001

Piane, M.D., Vorno, M., Pedone, A., Dovesi, R., Ugliengo, P. Large-Scale B3LYP Simulations of Ibuprofen Adsorbed in MCM-41. Mesoporous Silica as Drug Delivery System. The Journal of Physical Chemistry, 118, 26737-26749 (2014). https://doi.org/10.1021/jp507364h

Ribeiro, A.P.B., Moura, J.M.L.N., Grimaldi, R., Gonçalves, L.A.G. Interesterificação Química: Alternativa para Obtenção de Gorduras Zero Trans. Quimica Nova, 30, 1295-1300 (2007). https://doi. org/10.1590/S0100-40422007000500043
Rozenaal, A. Interesterification of Oils and Fats. Inform, 3, 1232-1237 (1992).

Schuchardt, U., Sercheli, R., Vargas, R.M. Transesterification of Vegetable Oils: A Review. Journal of the Brazilian Chemical Society, 9, 199-210 (1998). https://doi.org/10.1590/S010350531998000300002

Schwanke, A.J., Pergher, S.B.C. Peneiras Moleculares Mesoporosas MCM-41: Uma Perspectiva Histórica, o Papel de Cada Reagente na Síntese e Sua Caracterização Básica. Perspectiva, 36, 113125 (2012).

Silva, R.C., Gioielli, L.A. Propriedades Físicas de Lipídios Estruturados Obtidos a Partir de Banha e Óleo de Soja. Revista Brasileira de Ciências Farmacêuticas, 42, 223-235 (2006). https://doi. org/10.1590/S1516-93322006000200007

Soares, F.A.S.M., Silva, R.C., Silva, K.C.G., Lourenço, M.B., Soares, D.F., Gioielli, L.A. Effects of Chemical Interesterification on Physicochemical Properties of Blends of Palm Stearin and Palm Olein. Food Research International, 42, 1287-1294 (2009). https://doi.org/10.1016/j.foodres.2009.03.022

Stewart, J.J.P., MOPAC: A Semiempirical Molecular Orbital Program. Journal of Computer-Aided Molecular Design, 4, 1-105 (1990). https://doi. org/10.1007/BF00128336

USDA (United States Department of Agriculture), Oilseeds word markets and trade. Foreign Agricultural Service. Approved by the World Agricultural Outlook Board USDA. p.70 (2015).

Vallet-Regi, M., Rámila, A., del Real, R.P., PérezPariente, J. A New Property of MCM-41: Drug Delivery System. Chemistry of Materials, 13, 308311 (2001). https://doi.org/10.1021/cm0011559

Xie, W., Zang, X. Immobilized Lipase on CoreShell Structured $\mathrm{Fe}_{3} \mathrm{O}_{4}-\mathrm{MCM}-41$ Nanocomposites as a Magnetically Recyclable Biocatalyst for Interesterification of Soybean Oil and Lard. Food Chemistry, 194, 1283-1292 (2016). https://doi. org/10.1016/j.foodchem.2015.09.009

Xie, W., Zang, X. Covalent Immobilization of Lipase onto Aminopropyl-Functionalized HydroxyapatiteEncapsulated-C-Fe $\mathrm{O}_{3}$ Nanoparticles: A Magnetic Biocatalyst for Interesterification of Soybean Oil. Food Chemistry, 227, 397-403 (2017). https://doi. org/10.1016/j.foodchem.2017.01.082

Wang, T., Wu, G., Guan, N., Li, L. Nitridation of MgOLoaded MCM-41 and its Beneficial Applications in Base Catalyzed Reactions. Microporous Mesoporous Materials, 148, 184-190 (2012). https://doi.org/10.1016/j.micromeso.2011.07.024

Yang, Z., Xie, W. Soybean Oil Transesterification Over Zinc Oxide Modified With Alkali Earth Metals. Fuel Processing Technology, 88, 631-638 (2007). https://doi.org/10.1016/j.fuproc.2007.02.006 